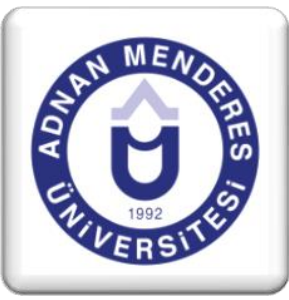

\title{
Üstün Yetenekli Ortaokul Öğrencilerinin Fen Öğrenmede Zihinsel Risk Alma Davranıșlarının Sınıf Düzeyi ve Cinsiyet Değişkenleri Açısından İncelenmesi ${ }^{1}$
}

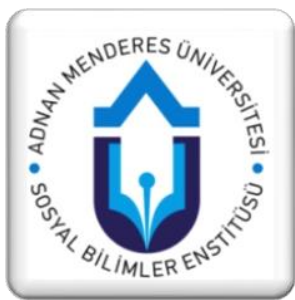

Emine Münevver AKDAĞ $\breve{G}^{2,}$ Mustafa Serdar

KÖKSAL ${ }^{3}$, Pelin ERTEKIN ${ }^{4}$

\section{ÖZET}

$\mathrm{Bu}$ çalışmanın amacı üstün yetenekli ortaokul öğrencilerinin fen öğrenmede zihinsel risk alma davranışlarının cinsiyet ve sınıf düzeyi açısından incelenmesidir. Çalışmada 53 altıncı, yedinci ve sekizinci sınıf üstün yetenekli öğrenci yer almıştır. Çalışmada veri toplama aracı olarak, fen bilimleri başarı testi, zihinsel risk alma ölçeği ve bireysel bilgi formu kullanılmıştır. Araştırmadan elde edilen verilerin analizinde değişkenler arasındaki ilişkiyi belirlemek için Spearman Rho korelasyon katsayısı hesaplanmıștır, karșılaștırmalar için ise Kruskal Wallis testi ve Mann-Whitney U testi kullanılmıştır. Araştırmanın bulguları üstün yetenekli öğrencilerin fen öğrenmede zihinsel risk alma ile fen bilimleri başarısı arasında istatistiksel olarak anlamlı negatif bir ilişki olduğunu göstermiştir. Karşılaştırmalara ilişkin bulgular ise 8. sınıfların diğer sınıflardan istatistiksel olarak anlamlı bir şekilde daha düşük fen öğrenmede zihinsel risk alma davranışı düzeylerine sahip olduklarını göstermiştir. Fakat cinsiyet açısından gruplar arasında zihinsel risk alma düzeylerinde anlamlı bir farklılık gözlenmemiştir.

Anahtar Kelimeler: Üstün Yetenekliler, Fen Öğrenmede Zihinsel Risk Alma, Akademik Başarı, Cinsiyet, Sınıf Düzeyi

\section{Investigating Gifted Middle School Students' Intellectual Risk Taking Behaviors in Learning Science across Gender and Grade}

\begin{abstract}
The purpose of this study is to examine intellectual risk taking levels of middle school gifted students in learning science in terms of gender and grade level. The study is consisted of 53 sixth, seventh and eighth grade gifted students. As data collection tools, science achievement test, intellectual risk taking scale and personal information form were used. Collected data were analyzed by Spearman Rho for associations, Kruskal Wallis Test and MannWhitney $U$ tests for comparisons. The findings revealed that there was a statistically significant negative relationship between science achievement and intellectual risk taking levels of middle school gifted students. Findings about the comparisons showed that eight grade student had lower levels of intellectual risk taking than seventh and sixth grade students. But there was no significant difference in intellectual risk taking levels in terms of gender.
\end{abstract}

Key words: Gifted Students, Intellectual Risk Taking Levels in Learning Science, Science Achievement, Gender, Grade

1 Bu çalışma, 24-25 Haziran 2016 tarihleri arasında Interdisciplinary Research Foundation tarafindan Polonya-Krakow'da düzenlenen "2016 International Conference on Gender Studies” isimli konferansta sözlü bildiri olarak sunulmuştur.

2 Doktora Öğrencisi, İnönü Üniversitesi, Eğitim Bilimleri Enstitüsü, emimegul@gmail.com

3 Doç. Dr., Hacettepe Üniversitesi, Eğitim Fakültesi, Özel Eğitim Bölümü, bioeducator@gmail.com

4 Arş. Gör., İnönü Üniversitesi, Eğitim Fakültesi, Matematik ve Fen Bilimleri Eğitimi Bölümü, pelin.ertekin@inonu.edu.tr 


\section{Giriș}

Bilim ve teknolojinin sürekli ve hızlı değişimi, bireylerin zihinsel, duyuşsal ve psikomotor becerilerinin gelişimi amaci ile gerçekleştirilen öğrenme faaliyetlerini doğrudan etkilemektedir. Bu durumun sonucu olarak bilgi edinim sürecinde bireyin, edilgen bir rol sergilemekten ziyade aktif, araştıran, sorgulayan, özgüveni yüksek, işbirlikli bir şekilde çalışmaya istekli olan, kendisini doğru bir şekilde ifade edebilen ve çevresi ile etkileşime geçebilen bir öğrenen olması beklenmektedir. $\mathrm{Bu}$ özellikler fen bilimleri öğretim programında bireylerin fen okuryazarı olması şeklinde ifade edilmektedir (MEB, 2013). Bu bağlamda öğrencilerin bilgiye ulaşmada ve bilgiyi kullanmada, karşılaştığı problemleri bilimsel süreç becerilerini kullanarak çözmede, fen bilimleri ile ilgili sorunlar ve önerilen çözümler için olası riskleri, yararları ve eldeki seçenekleri değerlendirerek karar vermede ve ortaya bilimsel bir ürün koymada daha etkin olmaları hedeflenmektedir (MEB, 2013). Tüm bunlar için bireyin, risk alma süreçlerini içeren yaratıcı ve inovatif düşünme, girişimci olma gibi yaşam becerilerini sergilemesinin yanı sıra öğrenme sürecinde özellikle soru sorabilme, açılamalarda bulunma, onaylama gibi zihinsel risk almayı gerektiren durumlara da açik olması beklenmektedir (Akkaya, 2016).

Risk almayla ilgili olarak literatürde çeşitli tanımlar bulunmaktadır. Yaman ve Köksal (2014) risk alma davranışını 'bireylerin sonuçlarını tahmin edemedikleri, daha önce üzerinde performans göstermedikleri ve alternatiflerden haberdar olmadıkları durumlarda tepkide veya tahminde bulunmaya isteklilik' olarak tanımlamışlardır. Çiftçi (2006)'ye göre ise risk alma, "hata yapmaya, gündemde olmayan durumları savunmaya ya da kesinleşmiş bir çözümü bulunmayan problemlerle uğraşmaya karşı duyulan istekliliktir". Genel olarak risk alma davranışı, bireyin sonuçları hakkında kesin bilgisinin olmadığı fakat buna rağmen sergilediği davranışların tamamı şeklinde ifade edilebilir (Neihart, 1999; Rosenbloom, 2003). Risk alma davranışlarının sınıflandırılması ile ilgili olarak bazı araştırmalarda görüş birliğine varılmıştır (Galavoti ve Lovick, 1989; Gonzalez ve diğ. 1994; Irwin ve Millstein, 1992; Akt. Korkmaz, 2002). Buna göre çok geniş bir kapsama sahip olmakla birlikte risk alma davranışları: Trafikle ilgili risk alma davranışları, cinsellikle ilgili risk alma davranışları, madde kullanımı ile ilgili risk alma davranışları, tehlikeli sporlarla ilgili risk alma davranışları ve akademik veya zihinsel risk alma davranışları olmak üzere beş grupta toplanmaktadır. Benzer şeklide Neihart (1999) ise risk alma davranışlarını sosyal, duygusal, manevi, fiziksel ve zihinsel olmak üzere beş farklı kategoride ele almıştır. Her iki sınıflandırmada yer alan zihinsel risk alma davranışı, bireylerin öğrenme süreçlerine ilişkin çoklu seçimler hakkında karar verme durumlarını içermektedir.

Zihinsel risk alma sürecinde öğrenen bireyin risk altında olduğu durum, öğrenme sürecinde bireyin hata yapma ve akranlarından daha az düzeyde performans sergileme olasılığına sahip olmasıdır. Buradan hareketle zihinsel risk alan bireylerin tüm bu olasılıklara rağmen öğrenme sürecinde daha aktif bir katılım gerçekleştirmesi beklenmektedir. Korkmaz (2002) zihinsel risk alma davranışını, bireylerin öğrenme süreçlerinde karşılaştıkları zorlukları aşma isteği sonucunda sergiledikleri cesaretli davranışlar olarak tanımlamaktadır. Skarr (2009) ise zihinsel risk alma davranışını olağandışı ve zor olarak nitelendirilen akademik görevlerin tercih edilmesi olarak ifade etmektedir. Benzer şeklide Clifford (1991)'e göre zihinsel risk alabilen bireyler, öğretim ortamlarında zor görevleri tercih etmelerinin yanı sıra göreve odaklı olmaları nedeniyle başarısızlıkla sonuçlanan durumlarda özellikle duyuşsal açıdan hazırlıklı olabilmekte ve gerek başarısızlıklarının üstesinden gelebilmek için gerekse daha üretken olabilmek için kendilerine özel öğrenme stratejileri belirleyebilmektedirler. Buna göre zihinsel risk alma düzeyi yüksek öğrencilerin sınıfta geçici fikirleri paylaşma, 
akranlarına ya da öğretmene soru sorma, sınıfta tartışılan konu hakkında açıklama yapma, bir probleme ilişkin yeni ve alternatif çözümler sunmaya istekli olma, öğrendiği bilgileri yeni durumlara uydurma, yeni bilgiler edinme gibi davranışlar sergilemeleri beklenmektedir (Beghetto, 2009; House, 2002; Neihart, 1999; Strum, 1971; Tay, Özkan ve Tay, 2009).

Toplumda bilişsel, duyuşsal ve psikomotor öğrenme alanları açısından farklılık gösteren üstün yetenekliler, zihinsel risk almaya ilişkin birçok davranışı sergilemede yüksek potansiyele sahip öğrenenlerdir. Üstün yetenekli öğrenciler, özellikle fen bilimleri eğitiminde sunulan bilimsel problemlerin çözüm sürecinde tek bir çözüme odaklanmayarak, probleme ilişkinin olgunun sorgulanması gibi zihinsel risk almayı içeren davranışlara başvurabilmektedirler (Soares, 2016). Benzer şeklide akranlarına kıyasla fen bilimleri öğretim sürecinde yüksek düzeyde yaratıcı ve eleştirel düşünme gibi üst düzey zihinsel performans gösterebilmelerinin zihinsel risk almalarının bir sonucu olduğu söylenebilir (Rainwater ve Wittner, 2016). Tüm bu durumlar dikkate alındığında zihinsel risk alma davranışlarının akranları ile benzer şeklide üstün yetenekli öğrencilerin, özyeterlilik, fen bilimlerine yönelik motivasyon ve tutum gibi duyuşsal özelliklerinin yanı sıra akademik başarı gibi zihinsel performanslarını etkileyen önemli bir değişkendir (Beghetto, 2009; Clifford, 1991; House, 2002; Tay vd., 2009).

Literatürde yer alan çalışmalar incelendiğinde zihinsel risk alma ile öğrencilerin akademik başarıları arasında anlamlı bir ilişki bulunmaktadır (Özyılmaz Akamca, 2008). Sharma (2015)'ya göre öğrenme süreçlerine etkin bir şekilde katılarak akademik risk alabilen öğrenciler yüksek düzeyde akademik başarı gösterme eğilimine sahiptirler. Başarı düzeyleri farkl1 6. sınıf öğrencilerinin karşılaştııldığı bir çalışmada, başarılı öğrencilerin yeni çalışma konularını seçerek risk alma davranışı açısından daha istekli oldukları görülmüsstür (Peled, 1997). Tay ve diğerleri (2009), üstün yetenekli öğrencilerin risk alma düzeyleri ile problem çözme becerileri arasındaki ilişkiyi araştırmış ve bu iki değişken arasında yüksek oranda anlamlı bir ilişki olduğunu gözlemlemiştir. Çakır ve Yaman (2015) yürüttükleri çalışmada 208 ortaokul öğrencisinin zihinsel risk alma davranışları ile üst bilişsel farkındalık ve başarıları arasındaki ilişkiyi incelemişlerdir. Çalışmanın bulguları zihinsel risk almanın hem üst bilişsel farkındalık hem de akademik başarı ile anlamlı bir şekilde ilişkili olduğunu göstermiştir. Daşçı ve Yaman (2014) ise, 4. ve 8. sınıf öğrencilerinin zihinsel risk alma davranışlarının bilişsel gelişim düzeyine göre anlamlı farklılık göstermediği fakat sınıf seviyeleri arttıkça zihinsel risk alma davranışının azaldığını gözlemlemişlerdir. Benzer şekilde Atkins, Leder, O'Halloran, Pollard ve Taylor (1991)'nn lise düzeyindeki (7, 8, 9, 10 , 11 ve 12. sınıf) öğrenciler ile yürüttükleri çalışmalarında, öğrencilerin zihinsel risk alma eğilimlerinin sınıf düzeyi ile zıt bir şekilde azalma gösterdiği sonucuna varmışlardır. Öte yandan Baghetto (2009) çalışmasında ilköğretim öğrencilerinin zihinsel risk alma davranışlarının sınıf seviyeleri ilerledikçe artış gösterdiğini ve fene karşı ilgi, öz yeterlilik ve öğretmen desteği gibi duyuşsal değişkenler arasında pozitif bir ilişkinin olduğunu belirlemiştir.

Cinsiyet farklılıkları değişkeni ele alındığında ise risk alma davranışı ile arasındaki ilişkiyi açıklayan sınırlı sayıda çalışma yer almaktadır. Fesser, Martignon, Engel ve Kuntze (2010), dördüncü ve dokuzuncu sınıf düzeyindeki öğrencilerin zihinsel risk alma durumlarını incelemişler ve özellikle kızların erkeklere oranla zihinsel risk alma durumundan daha fazla kaçındıklarını belirlemişlerdir. Ayrıca bu sonucun Atkins ve arkadaşlarının (1991) bulgularını da desteklediği görülmüştür. Bu durumun aksine Akkaya (2016) tarafindan üstün yetenekli 4. sınıf öğrenciler ile gerçekleştirilen deneysel çalışmada ise öğrencilerin cinsiyetlerinin zihinsel risk alma davranışları üzerinde bir etkisinin olmadığını gözlemlenmiştir. Gerçekleştirilen tüm bu çalışmaların sonuçları incelendiğinde diğer 
öğrenen gruplarında olduğu gibi üstün yetenekli öğrencilerin de zihinsel risk alma davranışlarının özellikle sınıf seviyesi ile paralel bir şekilde geliştirilmesi gereken ve akademik başarılarını artırıcı bir değişken olduğu görülmektedir.

Tüm bu durumlardan hareketle bu çalışmada, üstün yetenekli ortaokul 6,7 ve 8 . sınıf öğrencilerinin zihinsel risk alma davranışlarının, fen bilimlerine yönelik akademik başarı düzeyleri ile arasındaki ilişkinin belirlenmesi ve sınıf düzeyi ve cinsiyet değişkenleri açısından karşılaştırılarak incelenmesi amaçlanmaktadır. Bu amaçla incelenen değişkenlerin zihinsel risk alma davranışlarını nasıl ve ne düzeyde etkileyeceğinin belirlenmesi, mevcut durumun doğasının anlaşılarak öğrencilerin zihinsel risk alma davranışlarının geliştirilmesinde önemli bir adım niteliği taşımaktadır.

\section{Yöntem}

Bu çalışmada nicel araştırma yaklaşımı içinde yer alan nedensel-karşılaştırmalı araştırma yöntemi kullanılmıştır (Fraenkel ve Wallen, 2003). Araştırmaya Bilim ve Sanat Merkezinde öğrenim gören ve uygun örnekleme yöntemiyle seçilen altıncı, yedinci ve sekizinci sınıf düzeyindeki toplam 53 üstün yetenekli öğrenci katılmıştır. Öğrencilere ilişkin betimsel bilgiler Tablo 2'de verilmektedir.

Araştırmada veri toplama araçları olarak fen bilimleri başarı testi, zihinsel risk alma ölçeği ve bireysel bilgi formu kullanılmıştır. Başarı Testi Aşut (2013) tarafından üstün yetenekli çocuklar üzerinde geliştirilmiştir. Test, fen bilimlerinin fizik (12 soru), kimya (17 soru) ve biyoloji (16 soru) gibi üç temel alanına ilişkin toplam 45 çoktan seçmeli sorudan oluşmaktadır. Testin güvenirlik değeri(KR-21) 0.92 , güçlük düzeyi 0.32 , ayırt edicilik düzeyi ise 0.62 olarak bulunmuştur. Araştırmada kullanılan bir diğer veri toplama aracı "Fen Öğrenmede Zihinsel Risk Alma Ölçeğì" Yaman ve Köksal (2014) tarafından 6., 7., ve 8. sınıf öğrenciler üzerinde adapte edilmiş bir ölçektir. Ölçek Likert tipteki 6 maddeden oluşmaktadır ve iç tutarlılık katsayısı .69 olarak bulunmuştur. Bu araştırma için hesaplanan iç tutarlılık katsayısı ise $0.78^{\prime}$ dir. Gurubun üstün yetenekli öğrencilerden oluşması nedeniyle açıklayıcı faktör analizi yapıldıktan sonra ölçeğin tek faktörlü bir yapıya sahip olduğu $(\mathrm{KMO}=76$, Barlett Küresellik Katsayısı $=92,59, \mathrm{p}=0.00)$, toplam varyansın tek faktörle \%49'unun açıklandığı, faktör yüklerinin ise 0.46 ile 0.84 arasında olduğu belirlenmiştir. Araştırmanın verileri normallik varsayımını sağlamaması ve örneklemin az sayıda kişiden oluşmasından dolayı veri analizinde non-parametrik testlerden Spearman Rho korelasyon testi, Kruskal Wallis karşılaştırma testi ve Mann Whitney U testi kullanılmıştır.

\section{Bulgular}

$\mathrm{Bu}$ başlık altında analizlerin gerektirdiği varsayımlara ilişkin bulgular, değişkenlere ilişkin tanımlayıcı istatistik değerleri ve çıarımsal istatistik analizleri ile ilgili sonuçlar sunulacaktır. Parametrik testlerin en önemli varsayımı olan normallik için iki farklı yol kullanılmıştır: basıklık-yatıklık değeri ve Shapiro-Wilk testi. Sonuçlar tablo 1'de sunulmaktadir. 
Tablo 1. Normallik varsayımına ilişkin bulgular

\begin{tabular}{llllccc}
\hline \multirow{2}{*}{ Değişkenler } & \multirow{2}{*}{ N } & \multirow{2}{*}{ Yatıklık } & \multirow{2}{*}{ Basıklık } & \multicolumn{3}{c}{ Shapiro-Wilk Testi } \\
\cline { 5 - 7 } & & & & İstatistik & sd & $p$ \\
\hline Zihinsel Risk Alma & \multirow{2}{*}{53} & 1.36 & 2.12 & 0.88 & 53 & $0.00^{*}$ \\
\cline { 5 - 7 } & & 0.38 & 0.20 & 0.97 & 53 & $0.38^{*}$ \\
\hline
\end{tabular}

$$
* p<.05
$$

Tablo 1'deki değerler fen öğrenmede zihinsel risk alma değişkeninin normallik varsayımını sağlamadığını göstermektedir. Bu sonuç dikkate alınarak bu araştırmada non-parametrik testler tercih edilmiştir. Çıkarımsal analizlere geçmeden önce değişkenlere ilişkin tanımlayıcı istatistik değerleri belirlenmiştir. Tablo 2'de değişkenlere ilişkin tanımlayıcı değerler sunulmaktadir.

Tablo 2. Değişkenlere ilişkin tanımlayıcı istatistik değerleri

\begin{tabular}{|c|c|c|c|c|c|}
\hline Değişkenler & Kategoriler & Alt Kategori & $\mathbf{N}$ & Ort & SS \\
\hline Zihinsel Risk Alma & - & - & 53 & 4.03 & 0.84 \\
\hline Akademik Başarı & - & - & 53 & 23.81 & 6.12 \\
\hline \multirow{4}{*}{ Cinsiyet } & \multirow[t]{2}{*}{$\overline{\mathrm{K}} 1 \mathrm{Z}$} & Zihinsel Risk Alma & \multirow[t]{2}{*}{23} & 4.21 & 0.68 \\
\hline & & Akademik Başarı & & 23.13 & 6.19 \\
\hline & \multirow[t]{2}{*}{ Erkek } & Zihinsel Risk Alma & \multirow[t]{2}{*}{30} & 3.90 & 0.93 \\
\hline & & Akademik Başarı & & 24.33 & 6.12 \\
\hline \multirow{6}{*}{ Sınıf Düzeyi } & \multirow[t]{2}{*}{ 6. Sinif } & Zihinsel Risk Alma & \multirow[t]{2}{*}{36} & 4.27 & 0.62 \\
\hline & & Akademik Başarı & & 21.47 & 4.42 \\
\hline & \multirow[t]{2}{*}{ 7. Sinif } & Zihinsel Risk Alma & \multirow[t]{2}{*}{7} & 4.36 & 0.33 \\
\hline & & Akademik Başarı & & 23.43 & 5.59 \\
\hline & \multirow[t]{2}{*}{ 8. Sinif } & Zihinsel Risk Alma & \multirow[t]{2}{*}{10} & 2.95 & 0.97 \\
\hline & & Akademik Başarı & & 32.50 & 3.75 \\
\hline
\end{tabular}

Tablo 2'deki değerler dikkate alındığında öğrencilerin ortalamanın üzerinde bir başarı ortalamasına ve zihinsel risk alma düzeylerine sahip oldukları gözlenmektedir. Fakat cinsiyet açısından ve sınıf düzeyi açısından aralarında farklılık olup olmadığı durumunu analiz etmek için çıkarımsal istatistik yapılmalıdır. Çıkarımsal karşılaştırmalardan önce zihinsel risk alma değişkeninin önemini ortaya koymak için akademik başarı ve zihinsel risk alma arasındaki ilişki analiz edilmiştir. Tablo 3 ve Tablo 4 fen öğrenmede zihinsel risk alma ve akademik başarı arasındaki ilişkiye ait analizleri sunmaktadır.

Tablo 3. Fen öğrenmede zihinsel risk alma ve akademik başarı arasındaki ilişkiye ait Spearman-Rho korelasyon testi sonucu

\begin{tabular}{lccc}
\hline Korelasyon Değişkenleri & N & Rho Değeri & $p$ \\
\hline Zihinsel Risk Alma-Akademik Başarı & 53 & -0.32 & $0.018^{*}$ \\
\hline
\end{tabular}

$$
* p<.05
$$

Korelasyon bulguları fen öğrenmede zihinsel risk alma davranışı ile akademik başarı arasında negatif bir ilişkinin olduğunu göstermektedir. Fakat bu bulgu sınıf düzeyinde ele alındığında bu iki değişken arasında istatistiksel olarak anlamlı bir ilişkinin olmadığı belirlenmiştir. Bununla beraber cinsiyet değişkeni ele alındığında iki değişkenin erkeklerde 
istatistiksel olarak anlamlı negatif bir ilişkiye sahip olduğu kızlarda ise anlamlı bir ilişkiye sahip olmadıkları belirlenmiştir (Bkz. Tablo 4).

Tablo 4. Fen öğrenmede zihinsel risk alma ve akademik başarı arasındaki ilişkinin sınıf düzeyi ve cinsiyet açısından analizine iliş̧in sonuçlar

\begin{tabular}{lcccc}
\hline Korelasyon Değişkenleri & Kategori & $\mathbf{N}$ & Rho Değeri & $\mathbf{p}$ \\
\hline & 6. Sinıf & 36 & 0.15 & 0.38 \\
\cline { 2 - 4 } Zihinsel Risk Alma-Akademik Başarı & 7. Sinıf & 7 & -0.26 & 0.57 \\
\cline { 2 - 5 } & 8. sınıf & 10 & 0.16 & 0.65 \\
\cline { 2 - 5 } & Erkek & 30 & -0.43 & $0.02 *$ \\
\cline { 2 - 4 }
\end{tabular}

$* p<.05$

Tablo 3 ve tablo 4'deki bulgular fen öğrenmede zihinsel risk almanın çalışma grubunda yer alan üstün yetenekliler bağlamında fen bilimleri başarısı açısından önemli olduğunu göstermektedir. $\mathrm{Bu}$ durumun belirlenmesi ile beraber çalışmanın ana değişkeninin sınıf düzeyi ve cinsiyet açısından farklılık gösterip göstermediği analiz edilmiştir. Cinsiyet açısından yapılan karşılaştırmaya ilişkin bulgu Tablo 5'de sunulmaktadır.

Tablo 5. Cinsiyet açısından zihinsel risk alma düzeylerine ilişkin fark testi sonucu (Mann Whitney U testi)

\begin{tabular}{lcccccc}
\hline Değişken & Kategori & $\mathbf{N}$ & Ortalama Sıra & $\boldsymbol{U}$ & $\boldsymbol{Z}$ & $\mathbf{p}$ \\
\hline \multirow{2}{*}{ Cinsiyet } & Erkek & 30 & 24.97 & \multirow{2}{*}{284} & \multirow{2}{*}{1.101} & \multirow{2}{*}{0.27} \\
\cline { 2 - 4 } & Kız & 23 & 29.65 & & \\
\hline
\end{tabular}

Tablo 5'deki sonuçlar fen öğrenmede zihinsel risk alma düzeylerinin kızlar ve erkekler arasında istatistiksel olarak anlamlı bir şekilde farklılaşmadığını göstermektedir. Sınıf düzeyi açısından yapılan fark testi sonuçları ise Tablo 6'da sunulmaktadır.

Tablo 6. Sınıf Düzeyi Açısından Zihinsel Risk Alma Düzeylerine İlişkin Fark Testi Sonucu (Kruskal Wallis Testi)

\begin{tabular}{|c|c|c|c|c|c|c|}
\hline Değișken & Kategori & $\mathbf{N}$ & Ortalama Sira & Ki-kare & sd & p \\
\hline \multirow{3}{*}{ Sınıf Düzeyi } & 6. Sinıf & 36 & 30.90 & \multirow{3}{*}{16.23} & \multirow{3}{*}{2} & \multirow{3}{*}{$0.00 *$} \\
\hline & 7. Sinıf & 7 & 32.07 & & & \\
\hline & 8. Sinıf & 10 & 9.40 & & & \\
\hline
\end{tabular}

$$
* p<.05
$$

Tablo 6'daki sonuçlar fen öğrenmede zihinsel risk alma düzeylerinin 6.,7. ve 8. sinıflar arasında istatistiksel olarak anlamlı bir şekilde farklılaştığını göstermektedir. Kruskal Wallis testinde gözlenen farka ilişkin takip testinde iki karşılaştırmalar için Mann Whitney U testi kullanılmıştır. Bu test yardımıyla 3 grup ikili olarak ele alınmış ve gruplar ayrı ayrı analiz edilmiştir. Sonuçlar aşağıdaki tabloda (Tablo 7) sunulmaktadır. 
Tablo 7. Sınıf Düzeyi Açısından Zihinsel Risk Alma Düzeylerine İlişkin Takip Testlerinin Sonucu (Mann Whitney U Testi)

\begin{tabular}{|c|c|c|c|c|c|c|}
\hline Değişken & Kategori & $\mathbf{N}$ & Ortalama Sira & $U$ & $\bar{Z}$ & $p$ \\
\hline \multirow{6}{*}{ Sınıf Düzeyi } & 6. Sinıf & 36 & 21.93 & \multirow{2}{*}{123.50} & \multirow{2}{*}{0.08} & \multirow{2}{*}{0.93} \\
\hline & 7. Sinıf & 7 & 22.36 & & & \\
\hline & 6. Sinif & 36 & 27.47 & \multirow{2}{*}{37} & \multirow{2}{*}{3.82} & \multirow{2}{*}{$0.00^{*}$} \\
\hline & 8. Sinıf & 10 & 9.20 & & & \\
\hline & 7. Sinif & 7 & 13.71 & \multirow{2}{*}{2} & \multirow{2}{*}{3.24} & \multirow{2}{*}{$0.00 *$} \\
\hline & 8. Sinıf & 10 & 5.70 & & & \\
\hline
\end{tabular}

$* p<.05$

Tablo 7'de sunulan sonuçlara göre üstün yetenekli öğrencilerin zihinsel risk alma düzeyleri sınıf düzeyi açısından incelendiğinde 8. sınıfların diğer sınıf düzeylerine göre istatistiksel olarak anlamlı bir şekilde daha düşük düzeyde zihinsel risk alma davranışı sergiledikleri gözlemlenmiştir (6-8. Sinıf: $U=37, z=3.82, p<.05 ; 7-8$. Sinıf: $U=2, z=3.24, p<.05$ ). Öte yandan 7. Sinıf üstün yetenekli öğrencilerin zihinsel risk alma düzeylerinin 6. sinıflara oranla daha yüksek olduğu fakat bu farkın istatistiksel olarak anlamlı olmadığı belirlenmiştir $(\mathrm{U}=123.50, \mathrm{z}=0.08, \mathrm{p}=.93>.05)$.

\section{Sonuç, Tartışma ve Öneriler}

Üstün yetenekli ortaokul öğrencilerinin fen öğrenmede zihinsel risk alma davranışlarının cinsiyet ve sınıf düzeyi açısından incelendiği bu araştırma sonucuna göre öğrencilerin ortalamanın üstünde bir başarı ve zihinsel risk alma davranışına sahip oldukları gözlenmiştir. Bu durum, Özbay (2016) tarafından 2119 ortaokul öğrencileri ile gerçekleştirilen kapsamlı çalışmada "Fen Bilimleri Başarı Testi" (Aşut, 2013) ve "Fen Öğrenmede Zihinsel Risk Alma Ölçeği”"nden elde edilen ortalama puanlar $\left(\overline{\mathrm{X}}_{\text {Basarı }}=13.11 ; \overline{\mathrm{X}}_{\text {Zihinsel Risk }}=3.21\right)$ ile karşıllaştırmalı incelendiğinde anlaşılmaktadır. Benzer şekilde araştırmada başarı testinden elde edilen ortalama puanlar, Aşut (2013)'un üstün yetenekli ortaokul öğrencileri ile yürüttüğü çalışmasının bulgularını da destekler niteliktedir. Fen başarısı açısından üstün yetenekli öğrencilerin ortalamanın üzerinde puanlar alması beklenen bir durumdur, özellikle de sınıf düzeyi arttıkça başarının da artması beklenmektedir. Akkaya, Özbay ve Köksal (2016) yürüttükleri araştırmada üstün yetenekli öğrencilerin fen bilimleri başarısının akranlarından ve testin ortalama puanından fazla olduğunu rapor etmişlerdir. Arffa, Lovell, Podell ve Goldberg (1998) ile Seidenberg, Giordani, Berent ve Boll (1983) üstün yeteneklilerin üstün akademik başarılarının gelişmiş zihinsel performanslarının katkısıyla olabileceğini ifade etmişlerdir.

$\mathrm{Bu}$ çalışmada gözlenen diğer gelişmiş üstün yetenekli öğrenci özelliği zihinsel risk almadır. Çakır ve Yaman (2015) yürüttükleri çalışmada ortaokul öğrencilerinin fen bilimlerini öğrenmede zihinsel risk alma düzeylerini ölçmüşlerdir. Çalışmanın sonucunda katılımcıların ortalama zihinsel risk alma düzeylerinin yüksek olduğu rapor edilmiştir. Fen bilimlerini öğrenmede yüksek zihinsel risk alma davranışı, fen bilimleri sınıflarına ilişkin öğrenci algısıyla ilgili olabilir. Rakıcı (2004) çalışmasında 8. sınıf öğrencilerin fen bilimleri sınıflarını daha pozitif öğrenme çevreleri olarak algıladıklarını belirlemiştir. Bu durum dikkate alındığında gelecek çalışmalarda öğrenme çevresi algısı ve zihinsel risk alma düzeyi arasındaki ilişki ele alınabilir.

Bu çalışmada bir diğer önemli bulgu fen bilimleri başarısı ile zihinsel risk alma davranışı arasında negatif yönde bir ilişki tespit edilmiştir. Literatürde zihinsel risk alma davranışıyla fen başarısı arasındaki ilişkiyi doğrudan ele alan bir çalışmaya rastlanmamıştır. Ancak başarı 
için önemli görülen problem çözme becerisi ile zihinsel risk alma davranışı arasında pozitif yönde ilişki olduğu belirlenmiştir (Tay vd., 2009; Çınar, 2007). Bu çalışmalardaki bulgu mevcut araştırma sonuçlarıyla çelişmektedir. Tay ve diğerleri (2009) yaptıkları çalışmada üstün yetenekli öğrencilerin zihinsel risk alma davranışlarının problem çözme becerileriyle ilişkisini araştırmışlardır. Çalışmalarının sonuçları, üstün yetenekli öğrencilerin zihinsel risk alma düzeylerinin oldukça yüksek olduğunu ve öğrencilerin risk alma düzeyleri ile problem çözme becerileri arasında pozitif yönde yüksek oranda ilişki bulunduğunu göstermiştir. Yine Çınar (2007) tarafından yapılan bir çalışmaya göre problem çözme becerisinin artması ile öğrencilerin zihinsel risk alma davranışları ve başarıları artmaktadır. Burada gözlenen çelişkili bulgular üstün yetenekli öğrencilerin fen bilimleri başarısı ile zihinsel risk alma davranışı arasındaki ilişkinin daha büyük örneklemlerle, daha güçlü istatistiksel teknikler kullanılarak araştırılmasını gerektirmektedir.

$\mathrm{Bu}$ araştırmada öğrencilerin fen bilimleri başarı düzeyleri ile risk alma davranışlarının negatif yönde bir ilişki gösteriyor olmasının bir diğer açılayıcısı, örneklem grubunun bilişsel giriş özellikleri ve yaş gruplarının farklı olması olabilir. Nitekim araştırmada sınıf düzeyi ile zihinsel risk alma davranışı arasındaki ilişkiye bakılmış ve sınıf düzeyi arttıkça risk alma davranışının azaldığı görülmüştür. Bu durum literatürü desteklemektedir. Daşcı ve Yaman (2014) tarafindan yapılan bir çalışma 4. ve 8. sınıf öğrencilerinin eğitim kademesi değiştikçe risk alma düzeylerinin değiştiğini göstermektedir. Beghetto (2009) öğrencilerin yaşlarının artması ile zihinsel risk alma davranışlarının düştüğünü belirtmiş ve bu durumun; iyi derece alma, mükemmel sınav sonuçları, hatasız öğrenme gibi baskıların bir sonucu olduğunu literatürle açıklamıştır.

Çalışmanın bir diğer sonucu olarak zihinsel risk alma davranışında üstün yetenekli öğrenciler arasında, cinsiyet açısından önemli bir farklılaşma olmamıştır. Bu durum 5-13 yaşları arasındaki 112 çocuğun risk alma davranışlarında cinsiyet bazında farklılaşma olup olmadığının karşılaştıııldığı bir araştırma sonucuyla paralellik göstermektedir (Arenson, 1978; Akt: Korkmaz, 2002). Bu farksızlık öğrencilerin üstün yetenekli olma, aynı BİLSEM'de eğitim alma gibi özelliklerinden dolayı daha homojen bir grubu oluşturmalarıyla ilgili olabilir.

Zihinsel risk alma davranışı öğrencilerin, öğrenmek için gösterecekleri çaba üzerinde önemli bir etkiye sahip olan (Robinson ve Bell, 2012), başarıyla doğrudan ilişkili (Baghetto, 2009) duyuşsal bir özelliktir. Bu bağlamda zihinsel risk alma davranışının arttırılmasına yönelik çalışmaların yapılması önerilmektedir. Sınıf düzeyi ve cinsiyet dışında zihinsel risk almayla ilişkili olabileceği düşünülen başka değişkenlerin, zihinsel risk alma davranışıyla ilişkilerinin incelendiği çalışmaların yapılmasına ihtiyaç duyulmaktadır.

\section{KAYNAKÇA}

AKKAYA, G. (2016). Rol model içerikli animasyonların üstün yetenekli 4. Sinıf ögrencilerinin fen bilimleri dersinde zihinsel risk alma davranışları ve öğrenmelerine etkisi. Yayınlanmamış Doktora Tezi. İnönü Üniversitesi, Eğitim Bilimleri Enstitüsü, Malatya.

AKKAYA,G., ÖZBAY, H.E. \& KÖKSAL, M.S. (2016). TEOG fen ve teknoloji sınavının içerik bilgisi yönünden üstün yetenekli olan ve olmayan ortaokul öğrencileri ile fen bilgisi öğretmen adaylarının karşılaştırılması, Gazi Eğitim Bilimleri Dergisi, 2 (1), 1-12. 
ARFFA, S., LOVELL, M., PODELL, K., \& GOLDBERG, E. (1998). Wisconsin card sortingtest performance in above average and superior school children: Relationship to intelligence and age. Archives of Clinical Neuropsychology, 13, 713-720.

ATKINS, W. J., LEDER, G. C., O'HALlORAN, P. J., POLLARD, G. H. \& Taylor, P. (1991). Measuring Risk taking. Educational Studies in Mathematics, 32, 297 -308.

AŞUT, N. (2013). Üstün yetenekli ögrencilerin epistemolojik inançlarının fen ögrenmeye yönelik motivasyon düzeyi ve fen başarısıyla ilişkisi. Yayınlanmamış Yüksek Lisans Tezi. İnönü Üniversitesi, Eğitim Bilimleri Enstitüsü, Malatya.

BEGHETTO, R.A. (2009). Correlates of intellectual risk taking in elementary school science. Journal of Research in Science Teaching, 46(2), 210-223.

CLIFFORD M. M. (1991). Risk Taking: Theoretical empiricial and educational considerations. Educational psychologist. 26, 263-297.

ÇAKIR, E. \& YAMAN, S. (2015). Ortaokul öğrencilerinin zihinsel risk alma becerileri ve üst bilişsel farkındalıkları ile akademik başarıları arasındaki ilişki, Gazi Eğitim Bilimleri Dergisi, 1(2), 163-178.

ÇINAR, D. (2007). Illköğretim fen eğitiminde probleme dayalı öğrenme yaklaşımının üst düzey düşünme becerilerine ve akademik risk alma düzeyine etkisi. Yüksek lisans tezi, Selçuk Üniversitesi, Fen Bilimleri Enstitüsü, Konya.

ÇİFTÇİ, S. (2006). Sosyal bilgiler ögrretiminde proje tabanl öğrenmenin ögrrencilerin akademik risk alma düzeylerine, problem çözme becerilerine, erişilerine kalıcılığa ve tutumlarına etkisi. Yayımlanmamış Doktora Tezi, Selçuk Üniversitesi, Sosyal Bilimler Enstitüsü, Konya.

DAŞCI, A. D. ve YAMAN, S. (2014). Investigation of intellectual risk-taking abilities of students according to piaget's stages of cognitive development and education grade. Journal of Theoretical Educational Science, 7(3), 271-285.

FESSER, S., MARTIGGNON, L. ENGEL, J., \& KUNTZE, S. (2010). Risk perception and risk communication of school students: First empirical results from Riko-Stat. In C. Reading (Ed.) Proceedings from 8th International Conference on the Teaching of Statistics. Ljubljana, Slovenia: International Statistical Institute and International Association for Statistical Education.

FRANKEL, J.R. \& WALLEN, N.E. (2003). How to Design and Evaluate Research in Education, (5th ed.). New York: Mcgraw-Hill Publishing.

HOUSE, D. J. (2002). An investigation of the effects of gender and academic self-efficacy on academic risk-taking for adolescent students. UMI ProQuest Digital Dissertations. UMI.

KORKMAZ, H. (2002). Fen eğitiminde proje tabanlı öğrenmenin yaratıcı düşünme, problem çözme ve akademik risk alma düzeylerine etkisi. Yayınlanmamış Doktora Tezi, Hacettepe Üniversitesi, Sosyal Bilimler Enstitüsü, Ankara.

MEB. (2013). İlköğretim kurumları (ilkokullar ve ortaokullar): Fen bilimleri dersi (3, 4, 5, 6, 7 ve 8. Sinıflar) öğretim programı. Ankara: Milli Eğitim Bakanlığı Yayınları.

NEIHART, M. (1999). Systematic risk-taking. Rooper Review, 21(4), 289-292. 
ÖZBAY, E. H. (2016). Ortaokul öğrencilerinin akademik başarılarının bilimsel epistemolojik inançlar ve zihinsel risk alma davranışları ile ilişkisinin incelenmesi. Yayınlanmamış Doktora Tezi. İnönü Üniversitesi, Eğitim Bilimleri Enstitüsü, Malatya.

ÖZYILMAZ AKAMCA, G. (2008). Illköğretimde analojiler, kavram karikatürleri ve tahmin-gözlem-açıklama teknikleriyle desteklenmiş fen ve teknoloji ĕgitiminin ögrenme ürünlerine etkisi. Yayınlanmamış Doktora Tezi, Dokuz Eylül Üniversitesi, İzmir.

PELED, I. (1997). Forms of passiveness encoding and risk taking of poor math learners, International Journal of Mathematical Education in Science and Technology, 28(4), 581-589.

RAIINWATER, C., \& WITTNER, N. (2016). Developing a rebel with a cause through creative risk-taking in gifted students. In M. K., Demetrikopoulos \& J. L., Pecore, (pp. 381-398). Interplay of Creativity and Giftedness in Science. Springer.

RAKICI, N. (2004). Eight grade students' perceptions of their science learning environment and teachers' interpersonal behavior. PhD Dissertation, The Graduate School of Natural and Applied Sciences, Middle East Technical University, Ankara.

ROBINSSON, L.E., \& BELL, A. (2012, June). Exploring adult risk propensity and academic risk-taking within the online learning environment. Paper presented at the Adult Education Research Conference (AERC), Saratoga Springs.

ROSENBLOOM, T. (2003) Risk evaluation and risky behavior of high and low sensation seekers. Social Behavior and Personality, 31, 375-386.

SEIDENBERG, M., GIORDANI, B., BERENT, S., \& BOLL, T. (1983). IQ level and performance of the Halstead-Reitan Neuropsychological Test Battery for older children. Journal of Consulting and Clinical Psychology, 51(3), 406-413.

SHARMA, S. (2015). Promoting risk taking in mathematics classrooms: The importance of creating a safe learning environment. The Mathematics Enthusiast, 12(1), 290.

SKAAR, N.R. (2009). Development of the adolescent exploratory and risk behavior rating scale. Unpublished Doctoral Dissertation. Minnesota University, Minneapolis, Saint Paul, ABD.

SOARES, L. (2016). Sciencing: Creative, Scientific Learning in the Constructivist Classroom. In M. K., Demetrikopoulos \& J. L., Pecore, (pp. 127-151). Interplay of Creativity and Giftedness in Science. Springer.

STRUM, I. S. (1971). The relationship of creativity and academic risk-taking among fifth graders: Final report. ERIC Document Reproduction Service No: ED046212.

TAY, B., ÖZKAN, D., \& TAY, B.A. (2009) The effect of academic risk taking levels on the problem solving abaility of gifted students. Procedia Social and Behavioral Sciences, 1, 1099-1104.

YAMAN, S., \& KÖKSAL, M. S. (2014). Fen öğrenmede zihinsel risk alma ve yordayıcılarına ilişkin algı ölçeği Türkçe formunun uyarlanması: geçerlik ve güvenirlik çalışması. Journal of Turkish Science Education, 11(3), 119-142. 